\title{
TRADIÇÃO E RUPTURA: PESOUISAS E PRÁTICAS DA ARTE IMPRESSA CONTEMPORÂNEA
}

\section{TRADITION AND RUPTURE: RESEARCH AND PRACTICES OF CONTEMPORARY PRINTED ART}

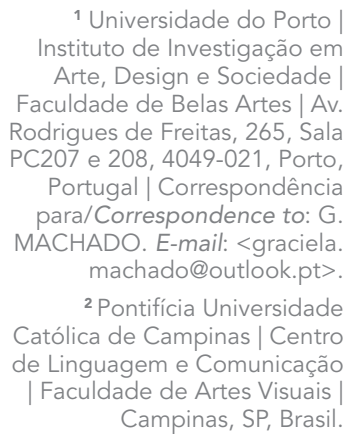

Como citar este artigo How to cite this article Machado, G. Almozara, P Tradição e ruptura: pesquisas e práticas da arte impressa contemporânea. Pós-Limiar v. 4, e215444, 2021. https:// doi.org/10.24220/2595 $9557 v 4 \mathrm{e} 2021 \mathrm{a} 5444$

Recebido e aprovado em $1 / 10 / 2021$

\author{
Graciela Machado ${ }^{1}$ \\ ORCID iD: 0000-0001-8730-7563 \\ Paula Almozara² \\ ORCID iD: 0000-0003-4239-2551
}

\section{RESUMO}

Este artigo apresenta questões pertinentes às pesquisas e práticas da arte impressa na contemporaneidade, partindo das ideias de tradição e ruptura, para refletir sobre abordagens poéticas que levam em conta elementos historicizados, indicando uma amplificação das formas de constituição dos objetos e projetos artísticos - em especial as elencadas na chamada do Dossiê "Tradição e Ruptura: Pesquisas e Práticas da Arte Impressa Contemporânea", da revista Pós-Limiar, que reuniu textos sobre estudos de caso, questões operacionais influenciadas pela imagem impressa e práticas intermeios.

\section{Palavras-chave}

Arte contemporânea. Belas-artes. Gravura. Impressão. Processos gráficos.

\section{ABSTRACT}

This article presents issues relevant to research and practices of contemporary printed art, starting from ideas of tradition and rupture to reflect on poetic approaches that take into account historicized elements, indicating an amplification of the forms of constitution of artistic objects and projects, especially those listed in the call for the Dossier "Tradition and Rupture: Research and Practice in the Contemporary Printed Art" of the jornal Pós-Limiar, which brought together texts on case studies, operational issues influenced by the printed image and intermediate practices.

\section{Keywords}

Contemporary art. Fine arts. Engraving. Print. Graphic processes.

\section{INTRODUÇÃO}

A proposta deste artigo é refletir sobre possibilidades poéticas, materiais e técnicas de práticas e processos conectados à arte impressa 
contemporânea. O uso dos termos "tradição" e "ruptura" apresentados no título determinam uma espécie de provocação, que implica em tensionamentos na abordagem de conceitos operacionais da produção artística.

Muito do interesse sobre as formas de instauração da arte impressa contemporânea está baseado na revisitação das questões técnico-históricas de processos e atividades percebidas como periféricas na "tradição" artística das Belas Artes, como a tipografia, a ilustração, a gravura, a impressão fotomecânica, entre outras. Para as poéticas visuais da atualidade, essa revisitação carrega em si propostas de alteração de paradigmas sobre a valoração extrínseca das práticas artísticas.

Nesse contexto, reunimos esforços entre nossos grupos de investigação do Instituto de Investigação em Arte, Design e Sociedade da Faculdade de Belas-Artes do Porto e do Grupo Produção e Pesquisa em Arte do Programa de Pós-Graduação em Linguagens, Mídia e Arte da PUC-Campinas para compor o Dossiê "Tradição e Ruptura: Pesquisas e Práticas da Arte Impressa Contemporânea" da revista Pós-Limiar no intuito de promover uma rede de pesquisa sobre a arte impressa. De início, foram propostos alguns tópicos de interesse para a discussão de conceitos e experimentações que colaborassem com a ampliação das noções associadas à produção gráfica. Considerou-se importante reunir abordagens que enfatizassem os processos e práticas da arte impressa no contexto contemporâneo, desenvolvendo estudos de caso e coletando depoimentos sobre experiências poéticas autorais, bem como as vivências em oficinas, ateliês e laboratório, destacando questões operacionais e metodológicas influenciadas pelo local de trabalho. Aspectos sobre uma noção de reconstituição de processos históricos para a arte contemporânea foi um ponto sensível, pensando inclusive na ideia de uma memória técnica condicionada ou não a um patrimônio histórico e à cultura material da imagem impressa para finalmente elencar práticas que estabelecessem nexos entre a imagem impressa, a poesia, a pintura, o cinema, a fotografia e a música.

Os artigos presentes no Dossiê desenvolveram de modo geral essas questões e foi possível inferir que há uma forte convergência que leva as investigações que apontam elementos considerados em sua materialidade e ressignificação histórico-técnico para o centro do debate teórico-conceitual na arte contemporânea.

Assim, o termo "ruptura" se apresenta como uma forma de advertir para a alteração de paradigmas relacionados à ideia de valoração das técnicas históricas de impressão no contexto das artes, sendo muito mais do que uma noção sobre abandono ou recusa dos processos tradicionais.

O interesse pela "arte impressa" tem se intensificado nos últimos tempos em função da percepção de seu trânsito inter e transdisciplinar, que abrange e conecta áreas que apresentam relações com a impressão e a reprodutibilidade técnica, podendo ser pensadas como um grande campo interligado para as pesquisas em poéticas visuais e que eram, até então, excluídas pelas suas características mais funcionais e comerciais, como a comunicação visual, processos gráficos e gravações industriais ${ }^{3}$, publicações editoriais, etc.

Nesse caso, nos referimos a processos de impressão gravação com maquinários industriais, como fresadoras CNC, máquinas de corte laser, Router CNC, corte de plasma, impressoras sublimativas indigo de grande porte, etc.
Toma-se como exemplo o livro Arte impreso, no qual o historiador e crítico Javier Maderuelo (2019) intenta uma proposta para se pensar os documentos e as obras impressas. O mérito do livro reside no fato de advertir para a necessidade de amplificação das formas de ordenação que coloquem em dúvida categorias teóricas que habitualmente servem para descrever obras de arte relacionadas a um ou outro estilo ou tendências, e que são, na maior parte dos casos, insuficientes ou inadequadas para pensar os diversos tipos de elementos que se reúnem em arquivos ou coleções. 
Observa-se que a categorização das produções que estão relacionadas ao que chamamos de arte impressa abarca uma miríade de possibilidades que por vezes tornam a categorização em si algo extremamente complexo. No entanto, sob a perspectiva do artista, essa classificação é provocativa e por vezes dispensáveis em um primeiro momento, considerando que o objetivo de produção está muito além de uma necessidade premente de classificação.

É importante pensar que essas ideias classificatórias são derivadas, em uma primeira análise, de fatores históricos que colaboraram para direcionar social e economicamente o que se tratava ou não por arte, impactando na percepção cultural sobre os objetos e produções e, por consequência, direcionando as atividades em uma distinção entre ars e techne (Greffe, 2013). A própria noção de arte e artista foi construída ao longo de um extenso período da história ocidental. Mas, notadamente, segundo Greffe (2013, p. 55), é com a passagem da produção artística do ateliê para a Academia que se observa que essa última, ao se tornar "um sistema para educar", trará como consequência uma codificação "de maneira quase oficial" dos saberes, e, assim, a Academia "começa, lenta, mas inexoravelmente, a produzir uma certa ortodoxia".

Os modelos apontados pela Academia passaram a exercer influência no modo de se perceber e pensar a arte com ressonâncias sobre boa parte da modernidade, atingindo de maneira indelével as manifestações contemporâneas.

Diante do exposto, a reflexão sobre as classificações é um ponto de inflexão complexo, mas considerar-se-á, por enquanto, que hoje uma afirmação classificatória por parte do artista sobre sua produção é uma escolha individual e está muito mais conectada a uma questão ou necessidade poética. Pode-se inferir que essa escolha, aparentemente inofensiva ou casuística, pode ser uma tomada de posição que reforça a abertura para as relações significativas e as possíveis conjecturas e especulações por parte de estudiosos e teóricos.

Os artistas, ao eliminarem premissas fechadas de contextualização de suas produções, permitem uma expansão do modo de se produzir e pensar a arte impressa e, inclusive, impelem dialogicamente para uma reflexão sobre a questão a partir de algo muito parecido com o que François Soulages determinou ao cunhar para a fotografia o conceito de fotograficidade. Essa ideia enfatiza o trânsito da imagem fotográfica entre diferentes estéticas, considerando que é o repertório ou o olhar do observador que decide sua condição - que pode se encontrar sob um contexto documental ou sob o ângulo da obra de arte (Soulages, 2010). Assim, é possível apropriar-se dessa ideia de "estar entre" para expandir a questão da arte impressa, considerando principalmente o trânsito ininterrupto entre documento e arte, no qual os dois podem inclusive coexistir, mas é importante advertir que estamos investindo aqui na percepção do artista e não propriamente na do observador, como pondera Soulages.

Ao determinarmos a questão sob a ótica do artista, é necessário considerar que a apropriação é um elemento fundamental de uma poética da arte impressa, que propositalmente levará em conta as conexões entre a história ou as camadas de significados pertencentes a uma escolha material. $O$ "estar entre" proposto por Soulages pode gerar tantos outros processos, que passam pela exacerbação de certas características, pela anulação, pelo apagamento, pela forma de exposição, pelas relações entre palavra e imagem, fotografia e imagem e pelos formatos, como dos livros, dos aparatos expositivos e dos aparatos óticos.

\section{ARTE IMPRESSA: UMA AMPLIFICAÇÃO NECESSÁRIA}

Notadamente a ideia de uma arte impressa que perpassa diversas proposições estéticas e se mescla de modo indelével a muitos projetos e 
que não se detém em categorizações estanques pode ser observada nesse trânsito entre documento e arte.

Do mesmo modo que tocamos a noção de fotografia e fotograficidade, podemos pensar também na apropriação da "palavra" como um elemento utilizado nas produções contemporâneas e que de imediato se apresenta em dois aspectos: o primeiro como um elemento gráfico-visual e o segundo como elemento semântico, nos quais nos encontramos mais uma vez em um trânsito funcional que deriva do uso, ou da percepção, da palavra-imagem e/ou da palavra-texto, considerando que a arte impressa perpassa os procedimentos de publicação, editoração e uso dos caracteres móveis.

Observa-se que muito do que podemos afirmar como sendo uma espécie de angústia classificatória, ou seja, elementos que não podem ser abarcados por um esquema tradicionalmente rígido, deriva das condições sobre o entendimento do que venha a ser "arte" e como o sistema cria representações e conceitos a esse respeito que impactam, pois, segundo Greffe (2013, p. 13), bem ou mal a produção artística está condicionada aos "regimes econômicos da arte" que "refletem a maneira específica como ela é reconhecida na sociedade e, por sua vez, delimitam as oportunidades e as restrições aos artistas".

No entanto, visto que a utilização de processos não hegemônicos pontua produções emblemáticas e transgressoras ao longo da cultura em diversos momentos históricos, observamos artistas que se valem de processos que não estão elencados como os pertencentes às estruturas classicamente definidas pelo mercado ou pelas ideias sistematizadas das "Belas-Artes" que, como afirmamos anteriormente, acabou por influenciar boa parte dos críticos e teóricos que assumiram ainda ao final do século XX certa ortodoxia em suas posições.

Nesse sentido, como apontado por Oliveira (2007), podemos tomar como exemplo a crítica à exposição de Leon Ferrari (1920-2013) realizada no Museu de Arte Moderna de São Paulo nos anos 1980 na qual o artista apresentou a série Plantas:

\begin{abstract}
A tônica da crítica, na época, repousava sobre os alicerces da relação forma versus conteúdo, mídia versus mensagem. E o que tais gravuras provocam é a negação de toda a relação de necessidade automática entre uma forma e um conteúdo determinados. A postura dos especialistas fica mais visível quando, no mesmo ano, Ferrari expõe na Pinacoteca do Estado de São Paulo, com sucesso de crítica, suas esculturas musicais, obras em aço inoxidável: abstratas, puras e lúdicas (Oliveira, 2007, p. 36).
\end{abstract}

Ainda segundo Oliveira, a produção gráfica do artista, que se valeu nesse contexto da heliografia (Figura 1), de carimbos e litografia, possui uma genealogia que remete às suas obras anteriores baseadas na caligrafia e que revela a relação com os processos gráficos que foram bastante evidenciados pelo contato de Ferrari com artistas como Regina Silveira e Julio Plaza quando de sua permanência em São Paulo.

Assim, o artista, que se dedica a explorar o tema e as práticas advindas dos infindáveis processos gráficos imperceptivelmente disseminados na e pela cultura ${ }^{4}$, estabelece, a duras penas, uma mudança de paradigmas que enfrentava uma indisposição do sistema das artes e de seus agentes, revelando, pelo menos no Brasil, certo descompasso e uma ideia um tanto quanto anacrônica e romantizada sobre as práticas e materiais da arte, em especial as obras feitas sobre papel e, mais ainda, as que se utilizam de processos fotomecânicos cuja a depreciação considerável ainda era pautada pela comparação entre as técnicas tradicionais da pintura e escultura.

Basta, para isso, aludir à maior aceitação das obras em esculturas da exposição que Ferrari realizou na Pinacoteca pouco tempo depois da exposição no Museu de Arte Moderna de São Paulo (Oliveira, 2007). 
Figura 1 - Leon Ferrari (Buenos Aires, Argentina 1920 - Buenos Aires Argentina, 2013). Cidade, 1980/07.

Nota: Cópia heliográfica $97.5 \times 98 \mathrm{~cm}$. Coleção MAM São Paulo. Doado pelo artista por intermédio do Núcleo Contemporâneo MAM-SP. Fonte: Foto de Romulo Fialdini.

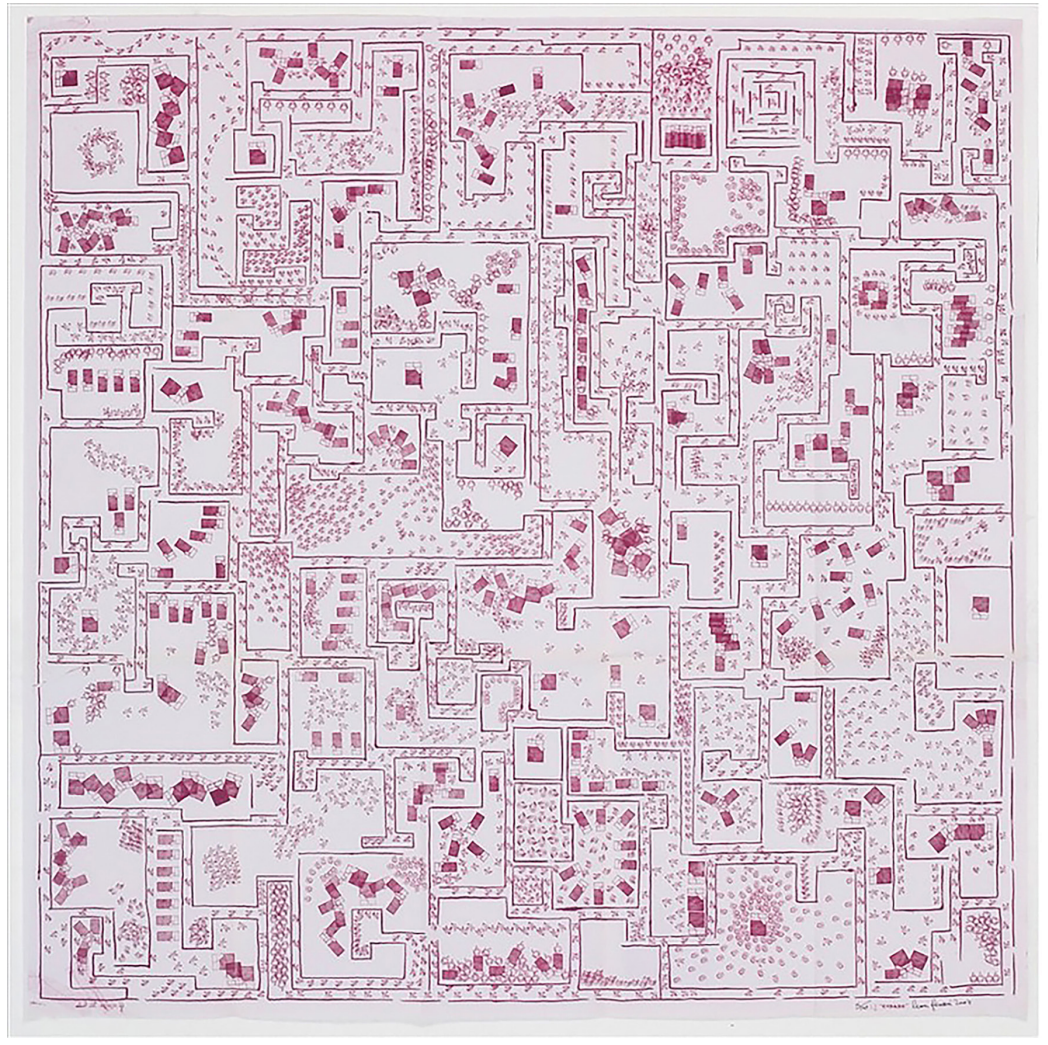

O que se observa é que nos inícios dos anos 60 e mais fortemente nos anos 70 do século XX a hegemonia da pintura e da escultura é, segundo Archer (2005), rompida para dar lugar a possibilidades de se pensar e fazer arte para além desse duopólio. Não que outras formas de se fazer arte não existissem anteriormente, seria ingênuo supor isso, mas sistematicamente foram negligenciadas por não corresponderem aos padrões estabelecidos e aceitos social e mercadologicamente.

Obviamente essa abertura se deu por conta dos posicionamentos dos artistas, imbricada a mudança de regime de produção entre o que consideramos como arte moderna e arte contemporânea (Cauquelin, 2005), englobando diversos e complexos fatores, sejam sociais, econômicos, políticos ou comunicacionais - questões essas que são, aparentemente e até certo ponto, alheias às especificidades do fazer artístico em si, mas que moldam a forma como se percebe a ideia de arte.

Considerando o interesse crescente por processos gráficos e fotográficos na arte contemporânea, que possibilitam a revisitação da produção de muitos artistas, é perceptível por meio das críticas e abordagens teórico-conceituais da época a relutância e incompreensão das mudanças paradigmáticas que já estavam no cerne dessas produções, em especial no uso dos recursos gráficos que se chocavam frontalmente com um modo ainda bastante ortodoxo de percepção da produção contemporânea.

A complexidade das produções que se valem hoje em dia dos processos gráficos e fotográficos aponta não mais para um cruzamento de fronteiras, mas para uma (pro)fusão que se estabelece pelo diálogo de e entre processos operativos que podem ser pensados em uma relação entre arte-técnica-história.

\section{PROCESSOS GRÁFICOS NA CONTEMPORANEIDADE}

Talvez aqui caiba, pois, insistir que a história da imagem abriga e dispersa amostras documentais de uma biodiversidade tecnológica em risco de 
perda ou exclusão. Consideramos que essa profusão de trilhos, percebida a partir do ateliê do artista, da oficina em espaço acadêmico, da vontade de acesso ao passado e que está assentada sobre um sentido de ruptura, precisa ser continuamente acionada.

Por sua vez, a informação disponível em bases de dados, repositórios e arquivos pode sustentar uma prática consciente do lastro tecnológico que foi criado em contexto comercial e reprodutivo, renovando, no presente, uma amplitude experimental nunca vista anteriormente.

Há um sentido revolucionário nesse acesso global ao conhecimento, ao mesmo tempo em que se forma a necessidade objetiva e pragmática de criar sistemas de trabalho baseados na pesquisa colaborativa. A complexidade dos dados e sistematização oportuna está aí para fazer transparecer valores atuais, de modo a compelir o artista a se situar e se posicionar perante uma diversidade rasgada, heterogênea, múltipla.

Esse princípio de ação é agora agilizado com um olhar crítico sobre um terreno tecnológico rotulado como excêntrico, obsoleto, onde a frieza e eficiência reprodutora de operador e processo não têm mais lugar, dando espaço ao autor empenhado em observar e conhecer as matérias mais essenciais para criar e assumir a importância do fazer técnico como uma expressão política de uma forma de atuação e resistência.

Insistimos sobre a importância em manter a curiosidade em torno de processos e materiais, dispositivos e instrumentos, herdados e usados ou desaparecidos, cuja identidade tecnológica e estranheza intrínseca se pode retomar, entendendo a imagem impressa quer como aquela que se usava em repartições e escritórios, gráficas, reprografias, como a formada a partir da matéria prima local, seja essa uma rocha, uma resina ou um pigmento. Afinal, não se pode deixar à parte os enredos tecnológicos, marcados pelo fascínio material onde o desconhecimento dos moldes de materialização e razão de existência se instalam passo a passo. A relação de reativação de uma imagem é transformativa e ativadora de outras tecnologias visuais com as quais a imagem impressa pode partilhar espaço. Tem arranque no fascínio material pelos processos de formação e seus constituintes a saltarem séculos e obrigarem o autor a posicionar-se perante o seu desconhecimento.

\section{CONSIDERAÇÕES FINAIS}

Intentamos uma reflexão sobre o desafio de se pensar a arte impressa na contemporaneidade e suas possibilidades operacionais e instaurativas, levando em conta os regimes de produção da arte e englobando o esforço de organização do Dossiê "Tradição e Ruptura: Pesquisas e Práticas da Arte Impressa Contemporânea", que empreende a constituição de uma rede de pesquisa que possa colaborar para um aprofundamento da prática e teoria das investigações sobre a arte impressa na contemporaneidade.

\section{REFERÊNCIAS}

Archer, M. Arte contemporânea, uma história concisa. São Paulo: Martins Fontes, 2005.

Cauquelin, A. Arte contemporânea, uma introdução. São Paulo: Martins Fontes, 2005.

Greffe, X. Arte e mercado. São Paulo: Iluminuras, Itaú Cultural, 2013. Disponível em: https://www.itaucultural.org.br/arte-e-mercado. Acesso em: 23 fev. 2021. 
Maderuelo, J. Arte impreso. Santander: Ediciones La Bahia, 2019.

Oliveira, E. D. G. Uma arte política ou uma política da arte: os pequenos sujeitos na arte do argentino León Ferrari. Revista Esboços: Histórias em Contextos Globais, v. 14, n. 18, p. 31-51, 2007. Disponível em: https:// periodicos.ufsc.br/index.php/esbocos/article/view/586. Acesso em: 20 fev. 2021.

Soulages, F. Estética da fotografia, perde e permanência. São Paulo: Editora SENAC, 2010. 